\title{
Quantitative Analysis of Candida Cell Wall Components by Flow Cytometry with Triple-Fluorescence Staining
}

\author{
Nogueira $\mathrm{MF}^{1,2,3}$, Istel $\mathrm{F}^{3}$, Jenull $\mathrm{S}^{3}$, Walker $\mathrm{LA}^{4}$, Gow $\mathrm{NA}^{4}$ and Lion $\mathrm{T}^{\star 1,2,5}$ \\ ${ }^{1}$ CCRI - Children's Cancer Research Institute, Vienna, Austria \\ ${ }^{2}$ Labdia - Labordiagnostik GmbH, Vienna, Austria \\ ${ }^{3}$ MFPL - Department of Medical Biochemistry, Medical University of Vienna, Max F. Perutz Laboratories, Campus \\ Vienna Biocenter, Vienna, Austria \\ ${ }^{4}$ MRC Centre for Medical Mycology, Aberdeen Fungal Group, School of Medicine, Medical Sciences \& Nutrition, \\ Institute of Medical Sciences, University of Aberdeen, Aberdeen, United Kingdom \\ ${ }^{5}$ Department of Pediatrics, Medical University of Vienna, Austria
}

*Corresponding author: Lion T, CCRI - Children's Cancer Research Institute, Vienna, Austria, Labdia Labordiagnostik GmbH, Vienna, Austria, Department of Pediatrics, Medical University of Vienna, Austria, E-mail: thomas.lion@ccri.at

Citation: Nogueira MF, Istel F, Jenull S, Walker LA, Gow NA, et al. (2017) Quantitative Analysis of Candida Cell Wall Components by Flow Cytometry with Triple-Fluorescence Staining. J Microbiol Modern Tech 2(1): 101

Received Date: August 21, 2017 Accepted Date: October 17, 2017 Published Date: October 20, 2017

\begin{abstract}
Detailed analysis of dynamic fungal cell wall components is crucial to our understanding of fungal systematics and the biology and physiology of fungal growth. In fungal pathogens this is of particular importance in examining their response to stress. However, current methodologies do not permit fast and accurate or quantitative analysis of cell wall carbohydrate components. Here, we provide a novel method permitting simultaneous quantitative analysis of the major cell wall components of Candida species relying on triplestaining with fluorescent labeling of chitin, $\beta$-glucans and mannans. Quantification is based on flow cytometry whereas qualitative analysis can be performed by direct imaging using fluorescence microscopy. We validated the method by determining the in vitro responses of different Candida species to the challenge of antifungal treatment with caspofungin. The assay facilitated rapid analysis of adaptive changes in cell wall composition upon caspofungin-induced damage. The method can be exploited for comprehensive quantitative analysis of Candida cell wall components, with relevant implications for clinical diagnosis of fungal infections in general.
\end{abstract}

Keywords: Candida spp.; Cell wall; Triple staining; Chitin; Glucans; Mannans; Flow cytometry

\section{Introduction}

Candida species represent the most prevalent opportunistic fungal pathogens associated with mortality rates as high as $30-40 \%$ in the immunocompromised clinical setting [1-5]. Although Candida albicans is still the most common yeast pathogen, other Candida species such as C. glabrata, C. krusei, C. tropicalis, C. parapsilosis, C. lusitaniae, C. guilliermondii and C. auris have emerged as important pathogens. The emergence is partly attributable to prophylactic treatment strategies, and poses a challenge for effective therapy due to inherent resistance to a number of antifungal agents [1,6-21].

The fungal cell wall is the first point of contact with the host, and therefore a key player in resistance and virulence. It mediates adherence to host tissues, antigenicity and modulation of the immune response [22-24]. The Candida cell wall is a complex and dynamic structure composed of an inner chitin layer, adjacent to an outer glucan layer containing $\beta$ - $(1,3)$-glucan and highly glycosylated mannoproteins. These are predominantly linked to the $\beta$ - $(1,3)$-glucan framework via GPI-remnants connected to $\beta$-(1,6)-glucan linkers [22,24-34]. The fungal cell wall responds to and counteracts environmental stresses or damage by dynamic remodeling of its composition, and therefore plays a key role in immune recognition, fitness and resistance to antifungal drugs, such as echinocandins [35-39]. Several studies in murine models of candidemia using C. albicans showed increased representation of $\beta$-glucan and chitin in the cell wall during infection and drug treatment [39-45].

Echinocandins are antifungal agents displaying high efficacy against most Candida species [46-48]. They act by inhibiting the enzyme $\beta$-(1,3)-glucan synthase Fks1, thereby preventing assembly of the $\beta$-glucan layer. As a consequence, the cell wall is 
weakened, rendering the cells more susceptible to lysis [46-49]. However, inhibition of a cell wall component can lead to defense mechanisms with compensatory enhancement of other cell wall components, repair and remodeling triggered by the Protein Kinase C (PKC) cell wall integrity pathway, including modification of the chitin layer $[18,35,36,45,50,51]$. The response increases echinocandin tolerance both in vitro and in vivo $[18,36,45]$. Quantitative analysis of Candida cell wall components has therefore become an important parameter in the assessment of stress responses potentially mediating resistance to antifungal therapy. Current methodological approaches rely on alkaline, acidic or enzymatic cell wall disruption to obtain individual components or isolated analysis of chitin and derivatives by spectroscopic methods [52-54,56]. Such approaches demand complex and timeconsuming analytical methods such as high-performance anion-exchange chromatography and pulsed amperometric detection (PAD) $[35,36,52,53,57-59]$.

Only recently, flow cytometry-based methodologies have emerged, enabling quantitative carbohydrate analysis of certain cell wall components [42,60-63]. However, current methods do not permit comprehensive analysis of all major cell wall components in a single assay. In addition, the analysis of live cells has not been possible. Here, we present a triple-staining flow cytometry-based method to determine the quantitative composition of the entire fungal cell wall. Six clinically relevant and phylogenetically diverse Candida spp., including C. albicans, C. glabrata, C. krusei, C. parapsilosis, C. lusitaniae and C. guilliermondii were employed to validate the method, demonstrating that exploitation of flow cytometry enables rapid and inexpensive quantitative analysis of all carbohydrate cell wall components.

\section{Materials and Methods}

\section{Strains, Growth Conditions and Preparation for Staining}

Candida strains used in this study are listed in Table 1. Strains were grown overnight in sterile-filtered yeast extract peptone dextrose (YPD) medium at $30{ }^{\circ} \mathrm{C}$ with agitation at $220 \mathrm{rpm}$. The cultures were subsequently diluted in fresh YPD medium to an $\mathrm{OD}_{600}$ of $\sim 0.3$. After $4 \mathrm{~h}$ of incubation at $30^{\circ} \mathrm{C}$ with agitation at $220 \mathrm{rpm}$, caspofungin (Merck \& Co., Whitehouse Station, NJ) was added at the concentrations indicated in Table 1 and Figure S1 (1/12.5 of the corresponding Minimal Inhibitory Concentration (MIC)). The cultures, untreated or treated with caspofungin, were incubated for an additional 3 hours, and were then harvested by centrifugation at $0.4 \mathrm{~g}$ for $2 \mathrm{~min}$. Cell pellets were washed once with $2 \mathrm{~mL}$ of $1 \mathrm{x}$ phosphate-buffered saline (PBS - NaCl, $\mathrm{KCl}$, $\mathrm{Na}_{2} \mathrm{HPO}_{4}, \mathrm{KH}_{2} \mathrm{PO}_{4}, \mathrm{dH}_{2} \mathrm{O}, \mathrm{pH}$ 7.4) and then resuspended with $500 \mu \mathrm{L}$ of $1 \mathrm{x}$ PBS. Aliquots of $100 \mu \mathrm{L}$ were transferred to fresh Eppendorf tubes, and the cells were harvested by centrifugation at $0.8 \mathrm{~g}$ for $2 \mathrm{~min}$ for subsequent single- or triple-staining of the cell wall components. Amber Eppendorf tubes were used for fluorescent staining to prevent dye degradation by exposure to light, while unstained controls were processed in standard Eppendorf tubes. The cell wall components were either stained individually or sequentially ( $\beta$-glucans $>$ mannans $>$ chitin), if triple-staining was performed, as outlined below. All centrifugation steps for cell collection were performed at $0.8 \mathrm{~g}$ for $2 \mathrm{~min}$.

\begin{tabular}{|c|c|c|c|}
\hline Strain & Designation & $\begin{array}{c}\text { MIC } \\
\text { Caspofungin }(\boldsymbol{\mu g} / \mathbf{m L})\end{array}$ & $\begin{array}{c}\text { Caspofungin } \\
\text { Stress }(\mathbf{n g} / \mathbf{m L})\end{array}$ \\
\hline C. albicans & SC5314 (77) & 0.03125 & 2.5 \\
\hline C. glabrata & ATCC2001 (www.atcc.org) & 0.125 & 10 \\
\hline C. krusei & ATCC6258 (www.atcc.org) & 0.0625 & 5 \\
\hline C. parapsilosis & ATCC22019 (www.atcc.org) & 0.25 & 20 \\
\hline C. lusitaniae & KK007 (clinical isolate) & 0.0625 & 5 \\
\hline C. guilliermondii & KK167 (clinical isolate) & 0.25 & 20 \\
\hline
\end{tabular}

Table 1: Candida strains, Minimal Inhibitory Concentrations (MICs) and caspofungin-stress concentrations used

\section{Staining of $\beta$-Glucans}

Candida cells were resuspended in $1 \mathrm{~mL}$ of cold $\left(4^{\circ} \mathrm{C}\right)$ flow cytometry (FC) blocking solution consisting of $0.5 \%$ Bovine Serum Albumin (BSA), 5\% HI-rabbit serum (Anti-rabbit IgG, New England Biolabs), 5 mM EDTA, and $2 \mathrm{mM} \mathrm{NaN}_{3}$ in 1x PBS by incubation for $30 \mathrm{~min}$ in a sample mixer (Hula Mixer, Invitrogen) at room temperature (RT). Cells were then collected by centrifugation and washed three times by resuspending in $1 \mathrm{~mL}$ of cold FC washing solution consisting of $0.5 \%$ BSA, $5 \mathrm{mM}$ EDTA, and $2 \mathrm{mM} \mathrm{NaN}_{3}$ in 1x PBS. The cells were collected by centrifugation. The Fc: Dectin-1 protein [Fc (human): Dectin-1 (mouse) (recombinant.), Adipogen] diluted to a final concentration of $1 \mu \mathrm{g} / \mathrm{ml}$ in FC blocking solution was used for binding of $\beta$-glucans. An aliquot of $100 \mu \mathrm{L}$ was used to resuspend the cells, and the solution was incubated for 60 min on ice. Cells were then collected by centrifugation and washed three times with $1 \mathrm{ml}$ of cold FC washing solution. A 1:200 dilution of Alexa Fluor 488-conjugated anti-human IgG Fc antibody (FC+488; Biolegend) was prepared in FC blocking solution. A total of $200 \mu \mathrm{L}$ of this solution was then used to resuspend the cells, followed by incubation for $45 \mathrm{~min}$ on ice. Upon Dectin-1/Fc+488 binding, cells were collected by centrifugation, and washed three times with $1 \mathrm{ml}$ of cold FC washing solution.

All centrifugation steps for cell collection described were performed at low speed ( $0.8 \mathrm{~g})$ for 2 min. To avoid cell agglomerates, a solution of Tween $20(0.05 \%)$ in 1x PBS or resuspension in FC buffer (1x PBS; 0.5 M EDTA; 0.5\% BSA; 0.01\% Tween 20) 
was occasionally added. Alternatively, cell clumps were disintegrated by sonication (max power, 3 s) [64]. For experiments not requiring visualization and quantification of live cells, fixation with $1 \%$ formaldehyde was optionally performed.

\section{Staining of Mannans}

ConcanavalinA Texas Red Conjugate (ConA-TRed) (LifeTechnologies) solution in 1x PBS was adjusted to a final concentration of $25 \mu \mathrm{g} / \mathrm{mL}$. A total volume of $1 \mathrm{~mL}$ was used to resuspend the cells, and samples were incubated in the dark at $30^{\circ} \mathrm{C}$ under shaking conditions at $500 \mathrm{rpm}$ on a thermoshaker (Eppendorf) for $45 \mathrm{~min}$. Cells were collected by centrifugation and the pellet was washed once with 1x PBS. Cells were finally resuspended in $500 \mu \mathrm{L} 1 \mathrm{x}$ PBS and transferred into FC tubes.

\section{Staining of Chitin}

A volume of $500 \mu \mathrm{L}$ Calcofluor White (CFW, fluorescent brightener 28; Sigma) were added to the samples at a final concentration of $25 \mu \mathrm{g} / \mathrm{mL}$, and samples were incubated for $10 \mathrm{~min}$ in the dark prior to flow cytometry analysis.

\section{Quantitative Measurement of Cell Wall Components by Flow Cytometry}

The cell wall components of Candida species including chitin, $\beta$-glucans and mannans were quantified by a flow cytometry-based approach. Fluorescently-labelled cell wall components were measured in a BD Fortessa cytometer (BD biosciences). Triple-stained cells were measured using BV421 (violet laser, $405 \mathrm{~nm}$ wavelength, $50 \mathrm{~mW}$ power), FITC (blue laser, $488 \mathrm{~nm}$ wavelength, $50 \mathrm{~mW}$ power) and TRed (red laser, $640 \mathrm{~nm}$ wavelength, $40 \mathrm{~mW}$ power) channels to detect the fluorescence of chitin, $\beta$-glucans and mannans labelled with CFW, Dectin-1/Fc+488 and ConA-TRed, respectively. Controls included single-stained and unstained samples for each species tested: caspofungin-stressed, single-stained cells yielding strong fluorescence signals, and unstressed cells without staining. A total of 10,000 cells were analyzed according to the manufacturer's guidelines. The flow cytometry data were analyzed using the Flowjo software (Flowjo LLC, USA, version 7.6.5.) to assess the relative amounts of individual cell wall components.

\section{Fluorescence Microscopy}

Candida cells were visualized under a confocal laser scanning microscope (CLSM, Zeiss LSM 700). The channels for bright field and fluorescence for DAPI, EGFP and TRed were applied to image the cell wall components chitin, $\beta$-glucans and mannans, respectively. A sample volume of $2.5 \mu \mathrm{L}$ was pipetted onto a glass slide (VWR, Vienna, Austria) and mixed with $2.5 \mu \mathrm{L}$ of CFW to yield a final concentration of $25 \mu \mathrm{g} / \mathrm{mL}$. A $1.5 \mathrm{~mm}$ cover glass slip (VWR, Vienna, Austria) was placed on top. Imaging was performed under constant-time laser exposure for untreated and treated samples. Images were analyzed using the Fiji software (Open source Java image processing, NIH image).

\section{Statistical Analysis}

The significance of differences between individual cell wall components of stressed (caspofungin-treated) versus unstressed cells was determined by using the T-test with one-tailed distribution for paired samples (Excel software). $P$ values $<0.05$ were considered significant. The calculations were based on three independent biological replicates.

\section{Results}

\section{Measurement of Candida Cell Wall Components by Flow Cytometry}

We modified and improved a flow cytometric methodology for simultaneous quantification of all major cell wall components of Candida species. A triple-staining assay was used to fluorescently label chitin, $\beta$-glucans and mannans. Chitin was directly labelled with Calcofluor White (CFW) (blue color). $\beta$-glucans were detected by conjugation of anti-human Alexa Fluor 488 (green color) with the protein Fc-Dectin1, and mannans were labelled by conjugating ConcanavalinA to Texas Red (ConA-TRed). The spectral overlap of the fluorescent dyes used is limited, thus permitting simultaneous analysis. The efficacy of the method was demonstrated by testing six different clinical Candida species, including reference strains of C. albicans, C. glabrata, C. krusei, and C. parapsilosis, as well as clinical isolates of $C$. lusitaniae and C. guilliermondii, for which no commercial reference strains are available. Fungal cells were exposed to exogenous stress by treatment with caspofungin at concentrations corresponding to 1/12.5 of the respective minimum inhibitory concentration (MIC) values for each strain (Table 1, Figure S1). Fungal cells challenged with caspofungin and unstressed controls were stained for chitin, $\beta$-glucans and mannans and subjected to subsequent quantitative analysis of individual cell wall components by flow cytometry. The differential changes observed in the cell wall composition of chitin, $\beta$-glucan and mannan are displayed in Figure 1. For all measurements revealing significant differences, the calculated p-values were $<0.05$. Upon caspofungin treatment, C. albicans showed a significant increase of chitin levels (1.6-fold) when compared to unstressed cells, whereas no changes in the $\beta$-glucan and mannan components beyond the standard deviation were observed (Figure 1A).

C. glabrata revealed significant enhancement of all three cell wall components after exposure to caspofungin compared to untreated controls, (chitin 2.4-fold, $\beta$-glucan 1.2-fold, mannan 3.9-fold; Figure 1B), and similar observations were made for C. krusei (chitin 3.1-fold, $\beta$-glucan 1.3-fold; mannan 2.2-fold; Figure 1C). For C. parapsilosis, a significant increase in chitin content was observed 
upon caspofungin treatment (1.2-fold), while no changes in $\beta$-glucan or mannan occurred (Figure 1D). In addition, clinical isolates of two Candida species including C. lusitaniae and C. guilliermondii were analyzed. While C. lusitaniae revealed significantly increased amounts of chitin (2.7-fold) and $\beta$-glucan (1.5-fold) upon caspofungin treatment (Figure 1E), C. guilliermondii showed significantly increased proportions of all three cell wall components (chitin 3.3-fold, $\beta$-glucan 1.7-fold, mannan 2.3-fold) (Figure $1 F)$. To correct spectral overlap among the different fluorophores, compensation controls were set up independently for each Candida species, using single-stained and unstained samples. These served as a baseline for the assessment of changes in the cell wall composition mediated by exposure to caspofungin (Figure S2).
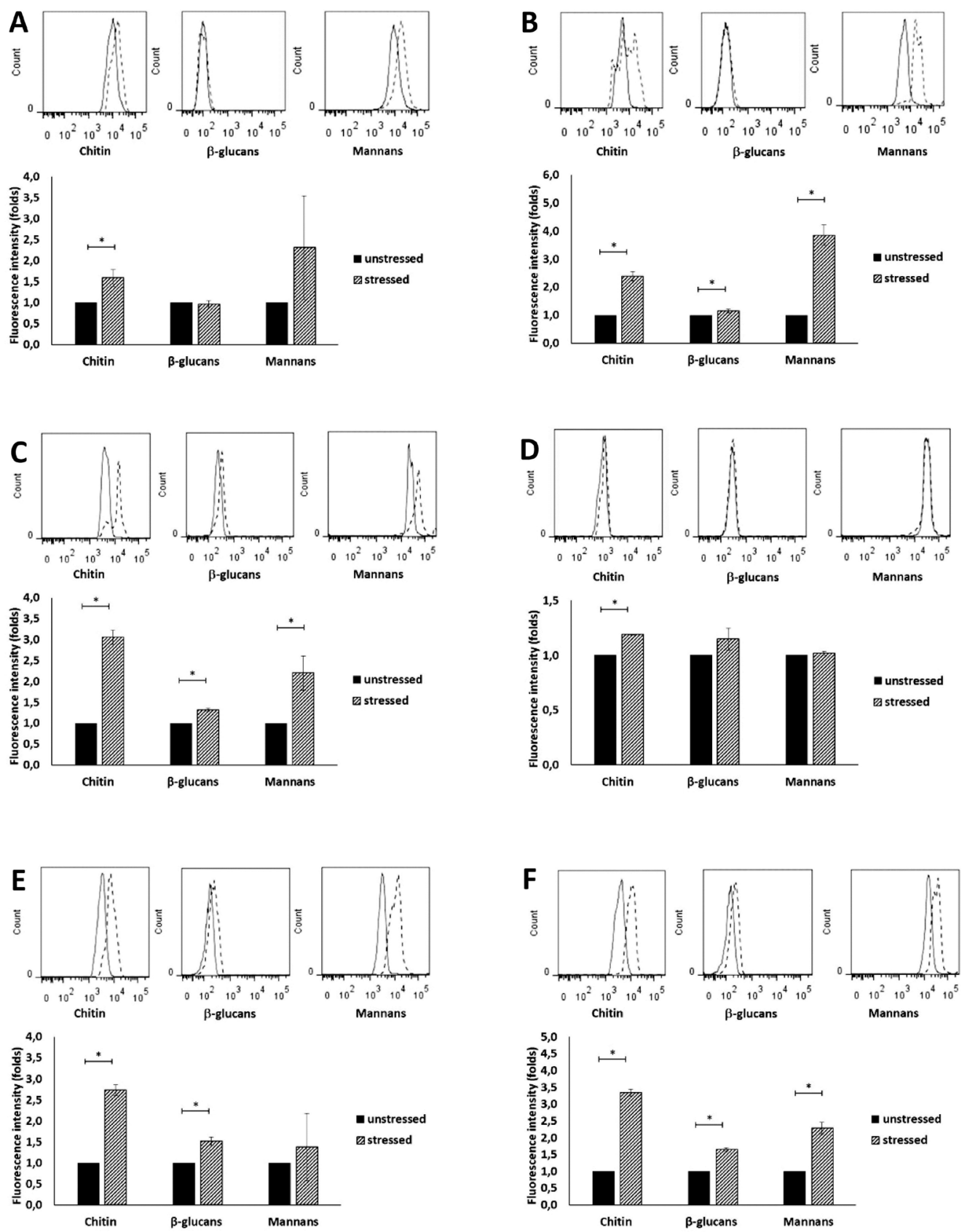

Figure 1: Quantitative analysis of cell wall components in Candida species by flow cytometry. The cell wall components chitin, $\beta$-glucans and mannans were quantified with a BD Fortessa cytometer using BV421, FITC and TRed lasers, respectively. A. C. albicans; B. C. glabrata; C. C. krusei; D. C. parapsilosis; E. C. lusitaniae; F. C. guilliermondii. The plots shown reflect unstressed (black peaks) and caspofungin-stressed cells (dashed peaks). Peak shifts on the flow cytometry plots from left to right indicate elevated fluorescence intensities reflecting an increase in the respective cell wall component. Quantification is indicated in folds of fluorescence intensity, with unstressed control samples set to 1 . The data shown reflect results of three independent replicates and error bars represent the standard deviation (SD). Horizontal bars with an asterisk mark significant differences between stressed cells and controls ( $p$ value $<0.05$ )

\section{Fluorescence Microscopy of Candida Species upon Caspofungin Challenge}

Triple-staining of Candida cell wall components was assessed by an independent technical approach using fluorescence microscopy. In addition to flow cytometric measurement, aliquots of each sample were subjected to imaging by confocal microscopy. 
Simultaneous triple-staining of chitin, $\beta$-glucans and mannans could be visualized in all Candida species tested (Figure 2 and 3 ). Evaluation by microscopy did not permit precise quantitative assessment of cell wall components, but facilitated the imaging of changes in cell wall composition triggered by exposure to caspofungin (Figure 2 and 3).

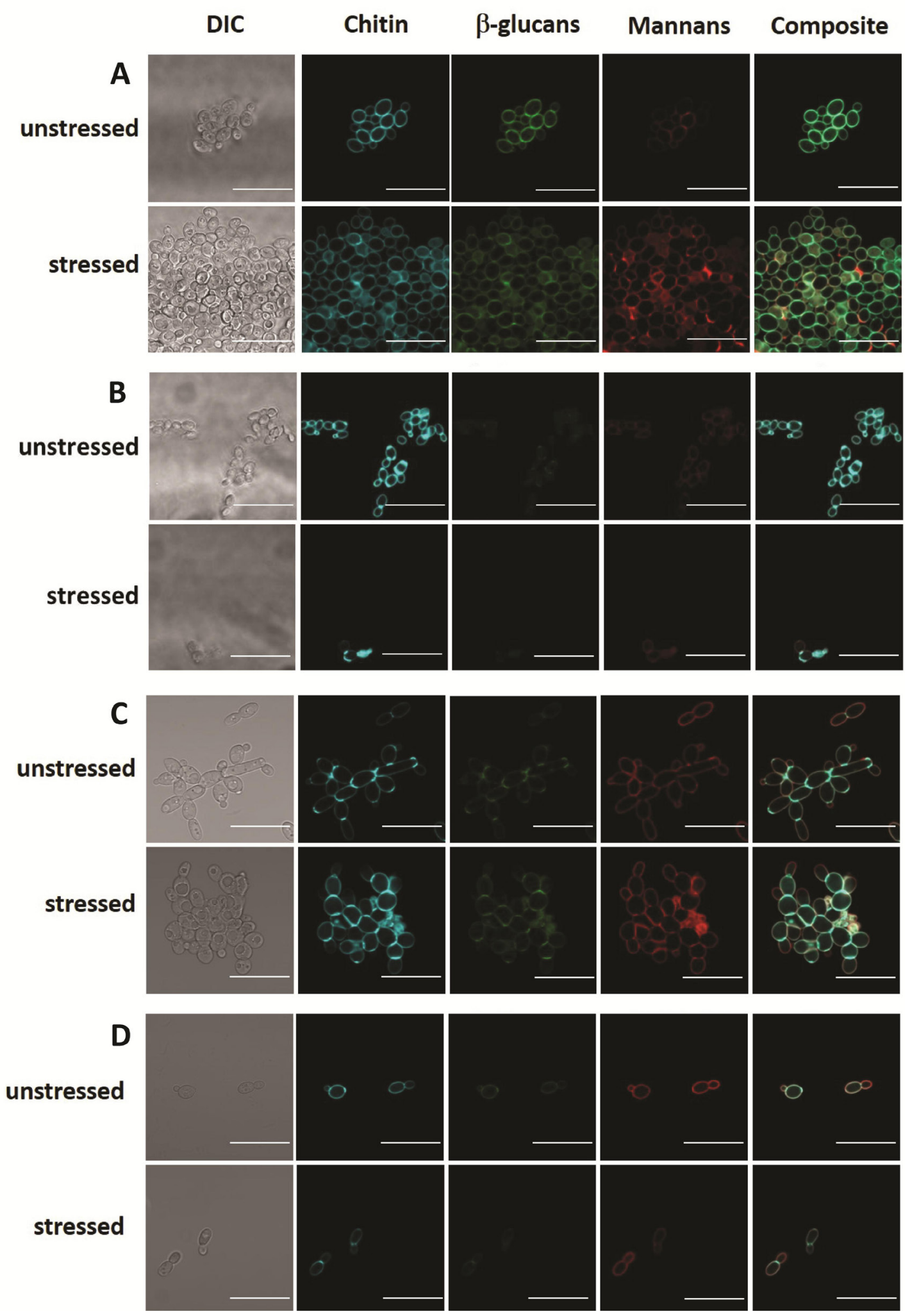

Figure 2: Confocal microscopy of cell wall components in Candida reference strains. Triple-staining of chitin, $\beta$-glucans and mannans fluorescently labelled with CFW, Alexa Fluor 488 and TRed, respectively. A. C. albicans; B. C. glabrata; C. C. krusei; D. C. parapsilosis. Differential Interface Contrast (DIC) and fluorescent pictures are shown. The designation "unstressed" corresponds to non-treated cells whereas "stressed" corresponds to caspofungin-stressed cells. Higher fluorescent color intensity reflects an increase in the respective cell wall component. Laser exposure time was kept constant for each individual species. Images were processed using Fiji software. Scale bars represent $20 \mu \mathrm{m}$ 


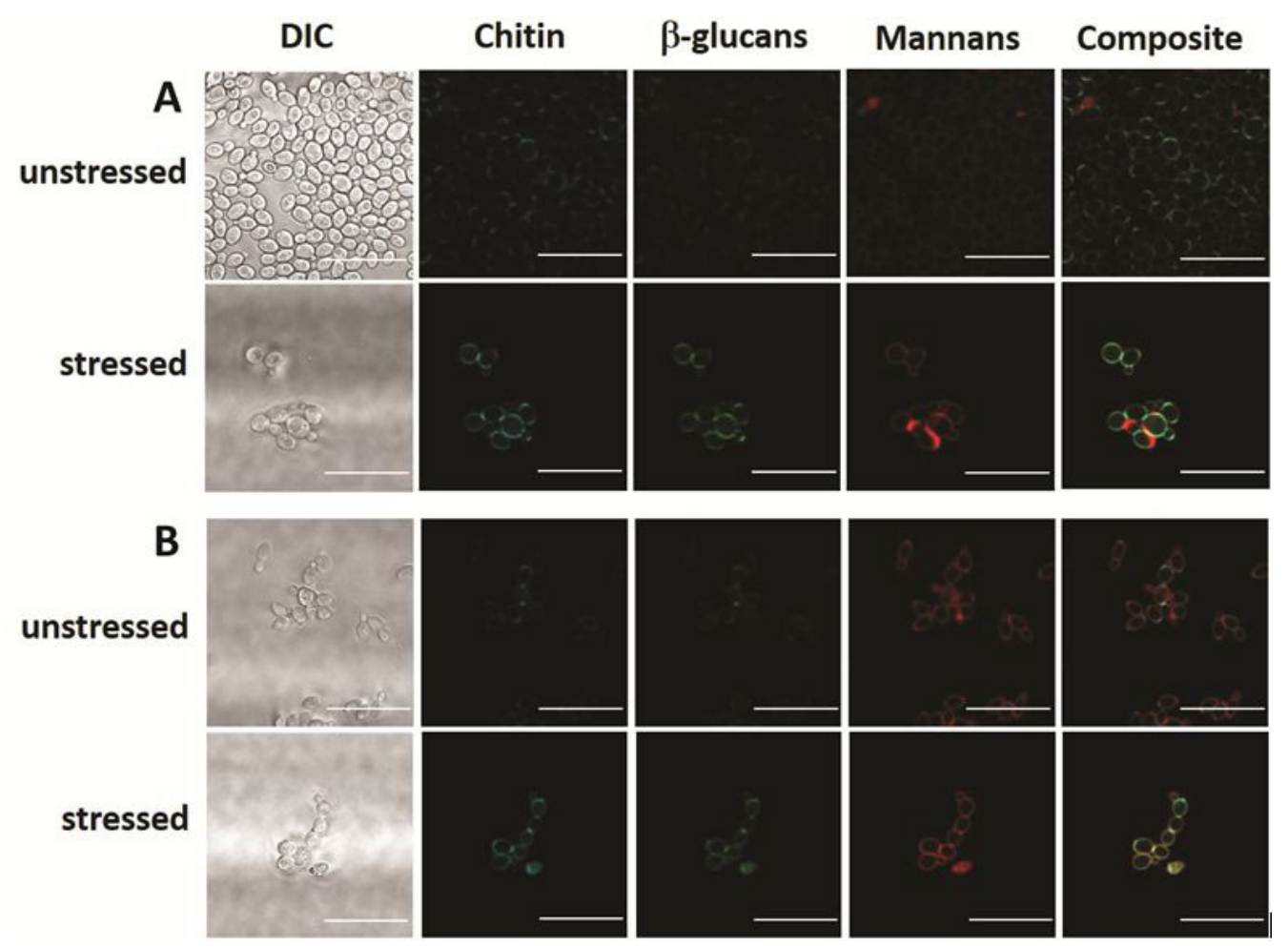

Figure 3: Confocal microscopy of cell wall components in clinical isolates of Candida species. Triple-staining of chitin, $\beta$-glucans and mannans fluorescently labelled with CFW, Alexa Fluor 488 and TRed, respectively. A. C. lusitaniae; B. C. guilliermondii. Differential Interface Contrast (DIC) and fluorescent pictures are shown. "Unstressed" corresponds to non-treated cells whereas "stressed" corresponds to caspofungin-stressed cells. Higher fluorescent color intensity reflects an increase in the respective cell wall component. Laser exposure time was kept constant for each individual species. Images were processed using Fiji software. Scale bars represent $20 \mu \mathrm{m}$

\section{Discussion}

The fungal cell wall is a point of contact with the host immune system, and plays a key role in responses to various stresses, ranging from host factors to antifungal treatment. Modulation of the cell wall composition is an important mechanism affecting the fitness of Candida spp. and facilitates the survival of the pathogens or immune evasion. Many studies have therefore focussed on the investigation of cell wall changes upon exposure to stress both in vitro and in vivo [1-3,9,29,39,40]. Challenge of $C$. albicans by different echinocandins including caspofungin was shown to result in upregulation of chitin synthesis leading to increased content of this constituent in the fungal cell wall $[18,32,36]$. Indeed, some strains exhibit "paradoxical growth" with enhanced growth in the presence of concentrations of caspofungin above the MIC [65-69]. These effects are regulated by activation of multiple signal transmission cascades triggered by the MAPK-Hog1/PKC and $\mathrm{Ca}^{2+} /$ calcineurin pathways [35]. Increased chitin amounts lead to enhanced cell wall resistance, elevated tolerance to antifungal treatment, and escape from the immune system [18,36,45]. Treatment with caspofungin and growth on alternative carbon sources can also lead to higher $\beta$-glucan content in the cell wall, and unmask this layer, exposing it to interaction with dectin-1 [41,42,70-72]. Dectin-1 is a C-type lectin serving as the prime $\beta$-glucan receptor, which mediates phagocytosis of Candida cells, and stimulates inflammation, T-cell activation and proliferation [73-75]. Unmasking of $\beta$-glucans can vary during the infectious process [41]. Mannans contribute to masking of the $\beta$-glucan layer, thereby preventing immune recognition, and elevated contents of this cell wall constituent can therefore promote evasion from immune attack $[63,75]$. Hence, changes in the fungal cell wall composition can mediate differential effects on the overall functional properties of the pathogens including their ability to escape from host immune response [76]. While the elevation of chitin and/or mannan content would result in increased resistance and improved fungal survival, the net effect of the observed changes involving $\beta$-glucans is less clear. Since the extent of cell wall modifications and the altered proportion of individual components may provide important information on the expected effect of adaptive changes, techniques permitting quantitative analysis of the cell wall components can provide important insights into fungal responses to various stresses including antifungal treatment.

Most existing methodologies which include mechanic and chemical disruption of the cells are based on alkaline and acidic hydrolysis of the fungal cell wall, and require rather laborious and meticulous controls to ensure complete extraction [35,36,52,53,57]. Flow cytometry has more recently been employed for analysis of individual cell wall components [42,60-63]. Here, we present a flow cytometry-based methodology facilitating simultaneous quantification of chitin, $\beta$-glucans and mannans of different Candida species based on triple-fluorescent staining. The use of fluorophores with low spectral overlap permits simultaneous detection of all major cell wall components. An important advantage of this method includes the ability to analyze live fungal cells and their cell wall modifications occurring upon exposure to specific stresses such as antifungal treatment. The entire procedure including cell 
preparation, staining and quantitative readout by flow cytometry with concomitant visualization by fluorescence microscopy for simultaneous analysis of two Candida species can be completed within one working day. The applicability of the approach presented has been demonstrated for some of the most frequently occurring and clinically highly relevant Candida species, including both reference strains and clinical isolates. The method can conceivably be applied to quantitative analysis of cell wall components in a broad spectrum of Candida species as well as other Candida-like fungi, and can contribute to improved understanding of stress responses in these pathogens, with important implications for research and ultimately for clinical management of fungal infections.

\section{Acknowledgements}

This work was supported by the European Commission within the FP7 Framework Programme [Fungitect-Grant No 602125]. We also thank Thomas Sauer, Vienna Biocenter Campus (VBC), Austria, for technical support at the FACS facility of the MFPL, Karl Kuchler, MFPL-Department of Medical Biochemistry, Medical University of Vienna, Max F. Perutz Laboratories, Campus Vienna Biocenter, Vienna, Austria and Ernst Thuer, Centre for Genomic Regulation, Barcelona, Spain, for advice on statistical approaches. Neil Gow acknowledges the support of the Wellcome Trust and the MRC Centre for Medical Mycology.

\section{References}

1. Pfaller MA, Jones RN, Doern GV, Fluit AC, Verhoef J, et al. (1999) International surveillance of blood stream infections due to Candida species in the European SENTRY Program: species distribution and antifungal susceptibility including the investigational triazole and echinocandin agents. SENTRY Participant Group (Europe). Diagn Microbiol Infect Dis 35: 19-25.

2. Edmond MB, Wallace SE, McClish DK, Pfaller MA, Jones RN, et al. (1999) Nosocomial bloodstream infections in United States hospitals: a three-year analysis. Clin Infect Dis 29: 239-44.

3. Morrell M, Fraser VJ, Kollef MH (2005) Delaying the empiric treatment of Candida bloodstream infection until positive blood culture results are obtained: a potential risk factor for hospital mortality. Antimicrob Agents Chemother 49: 3640-5.

4. Romani L (2004) Immunity to fungal infections. Nat Rev Immunol 4: 1-23.

5. Odds FC (1987) Candida infections: an overview. Crit Rev Microbiol 15: 1-5.

6. Pfaller MA, Andes DR, Diekema DJ, Horn DL, Reboli AC, et al. (2014) Epidemiology and outcomes of invasive candidiasis due to non-albicans species of Candida in 2,496 patients: data from the Prospective Antifungal Therapy (PATH) registry 2004-2008. Plos One 9: e101510.

7. Pfaller MA, Diekema DJ (2004) Twelve years of fluconazole in clinical practice: global trends in species distribution and fluconazole susceptibility of bloodstream isolates of Candida. Clin Microbiol Infect 1: 11-23.

8. Richardson M, Lass-Florl C (2008) Changing epidemiology of systemic fungal infections. Clin Microbiol Infect 4: 5-24.

9. Sanglard D, Ischer F, Bille J (2001) Role of ATP-binding-cassette transporter genes in high-frequency acquisition of resistance to azole antifungals in Candida glabrata. Antimicrob Agents Chemother 45: 1174-83.

10. Benjamin DK, Stoll BJ, Fanaroff AA, McDonald SA, Oh W, et al. (2006) Neonatal candidiasis among extremely low birth weight infants: risk factors, mortality rates, and neurodevelopmental outcomes at 18 to 22 months. Pediatrics 117: 84-92.

11. Fridkin SK, Kaufman D, Edwards JR, Shetty S, Horan T (2006) Changing incidence of Candida bloodstream infections among NICU patients in the United States: 1995-2004. Pediatrics 117: 1680-7.

12. Beyda ND, Lewis RE, Garey KW (2012) Echinocandin resistance in Candida species: mechanisms of reduced susceptibility and therapeutic approaches. Ann Pharmacother 46: 1086-96.

13. Van Asbeck EC, Clemons KV, Stevens DA (2009) Candida parapsilosis: a review of its epidemiology, pathogenesis, clinical aspects, typing and antimicrobial susceptibility. Crit Rev Microbiol 35: 283-309.

14. Hawkins JL, Baddour LM (2003) Candida lusitaniae infections in the era of fluconazole availability. Clin Infect Dis 36: 14-8.

15. Favel A, Michel-Nguyen A, Peyron F, Martin C, Thomachot L, et al. (2003) Colony morphology switching of Candida lusitaniae and acquisition of multidrug resistance during treatment of a renal infection in a newborn: case report and review of the literature. Diagn Microbiol Infect Dis 47: 331-9.

16. Barchiesi F, Spreghini E, Tomassetti S, Della Vittoria A, Arzeni D, et al. (2006) Effects of caspofungin against Candida guilliermondii and Candida parapsilosis. Antimicrob Agents Chemother 50: 2719-27.

17. Schwarzmuller T, Ma B, Hiller E, Istel F, Tscherner M, et al. (2014) Systematic phenotyping of a large-scale Candida glabrata deletion collection reveals novel antifungal tolerance genes. PLoS Pathog 10: e1004211.

18. Walker LA, Gow NA, Munro CA (2013) Elevated chitin content reduces the susceptibility of Candida species to caspofungin. Antimicrob Agents Chemother 57: 146-54.

19. Calvo B, Melo AS, Perozo-Mena A, Hernandez M, Francisco EC, et al. First report of Candida auris in America: Clinical and microbiological aspects of 18 episodes of candidemia. J Infect 73: 369-74.

20. Vallabhaneni S, Kallen A, Tsay S, Chow N, Welsh R, et al. (2017) Investigation of the First Seven Reported Cases of Candida auris, a Globally Emerging Invasive, Multidrug-Resistant Fungus-United States, May 2013-August 2016. Am J Transplant 17: 296-9.

21. Fairlamb AH, Gow NA, Matthews KR, Waters AP (2016) Drug resistance in eukaryotic microorganisms. Nat Microbiol 1: 92.

22. Richard A Calderone (2002) Candida and Candidiasis. ASM Press, Washington, USA.

23. Gordon S (2002) Pattern recognition receptors: doubling up for the innate immune response. Cell 111: 927-30.

24. Sundstrom P (2002) Adhesion in Candida spp. Cell Microbiol 4: 461-9.

25. Poulain D, Jouault T (2004) Candida albicans cell wall glycans, host receptors and responses: elements for a decisive crosstalk. Curr Opin Microbiol 7: $342-9$.

26. Gow NA, van de Veerdonk FL, Brown AJ, Netea MG (2011) Candida albicans morphogenesis and host defence: discriminating invasion from colonization. Nat Rev Microbiol 10: 112-22.

27. Ruiz-Herrera J, Elorza MV, Valentin E, Sentandreu R (2006) Molecular organization of the cell wall of Candida albicans and its relation to pathogenicity. FEMS Yeast Res 6: 14-29. 
28. Bulawa CE (1993) Genetics and molecular biology of chitin synthesis in fungi. Annu Rev Microbiol 47: 505-34.

29. Shaw JA, Mol PC, Bowers B, Silverman SJ, Valdivieso MH, et al. (1991) The function of chitin synthases 2 and 3 in the Saccharomyces cerevisiae cell cycle. J Cell Biol 114: 111-23.

30. Klis FM, de Groot P, Hellingwerf K (2001) Molecular organization of the cell wall of Candida albicans. Med Mycol 1: 1-8.

31. Klis FM, Mol P, Hellingwerf K, Brul S (2002) Dynamics of cell wall structure in Saccharomyces cerevisiae. FEMS Microbiol Rev 26: $239-56$.

32. Munro CA, Gow NA (2001) Chitin synthesis in human pathogenic fungi. Med Mycol 1: 41-53.

33. Roncero C (2002) The genetic complexity of chitin synthesis in fungi. Curr Genet 41: 367-78.

34. Calderone RA, Braun PC (1991) Adherence and receptor relationships of Candida albicans. Microbiol Rev 55: 1-20.

35. Munro CA, Selvaggini S, de Bruijn I, Walker L, Lenardon MD, et al. (2007) The PKC, HOG and Ca2+ signalling pathways co-ordinately regulate chitin synthesis in Candida albicans. Mol Microbiol 63: 1399-413.

36. Walker LA, Munro CA, de Bruijn I, Lenardon MD, McKinnon A, et al. (2008) Stimulation of chitin synthesis rescues Candida albicans from echinocandins. PLoS Pathog 4: e1000040.

37. Lesage G, Bussey H (2006) Cell wall assembly in Saccharomyces cerevisiae. Microbiol Mol Biol Rev 70: 317-43.

38. Wheeler RT, Fink GR (2006) A drug-sensitive genetic network masks fungi from the immune system. PLoS Pathog 2: e35.

39. Hopke A, Nicke N, Hidu EE, Degani G, Popolo L, et al. (2016) Neutrophil Attack Triggers Extracellular Trap-Dependent Candida Cell Wall Remodeling and Altered Immune Recognition. PLoS Pathog 12: e1005644.

40. Lionakis MS, Lim JK, Lee CC, Murphy PM (2011) Organ-specific innate immune responses in a mouse model of invasive candidiasis J Innate Immun. 3: 180-99.

41. Wheeler RT, Kombe D, Agarwala SD, Fink GR (2008) Dynamic, morphotype-specific Candida albicans beta-glucan exposure during infection and drug treatment. PLoS Pathog 4: e1000227.

42. Bain JM, Louw J, Lewis LE, Okai B, Walls CA, et al. (2014) Candida albicans hypha formation and mannan masking of beta-glucan inhibit macrophage phagosome maturation. Mbio 5: 01874-14

43. Mora-Montes HM, Netea MG, Ferwerda G, Lenardon MD, Brown GD, et al. (2011) Recognition and blocking of innate immunity cells by Candida albicans chitin. Infect Immun 79: 1961-70.

44. Wagener J, Malireddi RK, Lenardon MD, Koberle M, Vautier S, et al. (2014) Fungal chitin dampens inflammation through IL-10 induction mediated by NOD2 and TLR9 activation. PLoS Pathog 10: e1004050.

45. Lee KK, Maccallum DM, Jacobsen MD, Walker LA, Odds FC, et al. (2012) Elevated cell wall chitin in Candida albicans confers echinocandin resistance in vivo. Antimicrob Agents Chemother 56: 208-17.

46. Chen SC, Slavin MA, Sorrell TC (2011) Echinocandin antifungal drugs in fungal infections: a comparison. Drugs 71: 11-41.

47. McCormack PL, Perry CM (2005) Caspofungin: a review of its use in the treatment of fungal infections. Drugs 65: $2049-68$.

48. Sucher AJ, Chahine EB, Balcer HE (2009) Echinocandins: the newest class of antifungals. Ann Pharmacother 43: $1647-57$.

49. Pappas PG, Rex JH, Sobel JD, Filler SG, Dismukes WE, et al. (2004) Guidelines for treatment of candidiasis. Clin Infect Dis 38: 161-89.

50. Reinoso-Martin C, Schuller C, Schuetzer-Muehlbauer M, Kuchler K (2003) The yeast protein kinase C cell integrity pathway mediates tolerance to the antifungal drug caspofungin through activation of Slt2p mitogen-activated protein kinase signaling. Eukaryot Cell 2: $1200-10$.

51. Popolo L, Gualtieri T, Ragni E (2001) The yeast cell-wall salvage pathway. Med Mycol 1: 111-21.

52. Ip CC, Manam V, Hepler R, Hennessey JP (1992) Carbohydrate composition analysis of bacterial polysaccharides: optimized acid hydrolysis conditions for HPAEC-PAD analysis. Anal Biochem 201: 343-9.

53. Kapteyn JC, Hoyer LL, Hecht JE, Muller WH, Andel A, et al. (2000) The cell wall architecture of Candida albicans wild-type cells and cell wall-defective mutants. Mol Microbiol 35: 601-11.

54. Ibrahim M, Mahmoud AA, Osman O, Refaat A, El-Sayed el SM (2010) Molecular spectroscopic analysis of nano-chitosan blend as biosensor. Spectrochim Acta A Mol Biomol Spectrosc 77: 802-6.

55. Ibrahim M, Osman O (2009) Spectroscopic Analyses of Cellulose: Fourier Transform Infrared and Molecular Modelling Study. J Comput Theor Nanosci 6: 1054-8.

56. Ibrahim M, Osman O, Mahmoud AA (2011) Spectroscopic Analyses of Cellulose and Chitosan: FTIR and Modeling Approach. J Comput Theor Nanosci 8: 117-23.

57. Kogan G, Pavliak V, Masler L (1988) Structural studies of mannans from the cell walls of the pathogenic yeasts Candida albicans serotypes A and B and Candida parapsilosis. Carbohydr Res 172: 243-53.

58. Hardy MR, Townsend RR (1988) Separation of positional isomers of oligosaccharides and glycopeptides by high-performance anion-exchange chromatography with pulsed amperometric detection. Proc Natl Acad Sci USA 85: 3289-93.

59. Hardy MR, Townsend RR, Lee YC (1988) Monosaccharide analysis of glycoconjugates by anion exchange chromatography with pulsed amperometric detection. Anal Biochem 170: 54-62.

60. Costa-de-Oliveira S, Silva AP, Miranda IM, Salvador A, Azevedo MM, et al. (2013) Determination of chitin content in fungal cell wall: an alternative flow cytometric method. Cytometry A 83: 324-8.

61. Linden JR, Maccani MA, Laforce-Nesbitt SS, Bliss JM (2010) High efficiency opsonin-independent phagocytosis of Candida parapsilosis by human neutrophils. Med Mycol 48: 355-64.

62. Seider K, Gerwien F, Kasper L, Allert S, Brunke S, et al. (2014) Immune evasion, stress resistance, and efficient nutrient acquisition are crucial for intracellular survival of Candida glabrata within macrophages. Eukaryot Cell 13: 170-83.

63. Davis SE, Hopke A, Minkin SC, Montedonico AE, Wheeler RT, et al. (2014) Masking of beta(1-3)-glucan in the cell wall of Candida albicans from detection by innate immune cells depends on phosphatidylserine. Infect Immun 82: 4405-13.

64. Kaloriti D, Tillmann A, Cook E, Jacobsen M, You T, et al. (2012) Combinatorial stresses kill pathogenic Candida species. Med Mycol 50: 699-709.

65. Bizerra FC, Melo AS, Katchburian E, Freymuller E, Straus AH, et al. (2011) Changes in cell wall synthesis and ultrastructure during paradoxical growth effect of caspofungin on four different Candida species. Antimicrob Agents Chemother 55: 302-10. 
66. Chamilos G, Lewis RE, Albert N, Kontoyiannis DP (2007) Paradoxical effect of Echinocandins across Candida species in vitro: evidence for echinocandinspecific and candida species-related differences. Antimicrob Agents Chemother 51: 2257-9.

67. Moriyama B, Henning SA, Penzak SR, Walsh TJ (2012) The postantifungal and paradoxical effects of echinocandins against Candida spp. Future Microbiol 7: 565-9.

68. Rueda C, Cuenca-Estrella M, Zaragoza O (2014) Paradoxical growth of Candida albicans in the presence of caspofungin is associated with multiple cell wall rearrangements and decreased virulence. Antimicrob Agents Chemother 58: 1071-83.

69. Stevens DA, Ichinomiya M, Koshi Y, Horiuchi H (2006) Escape of Candida from caspofungin inhibition at concentrations above the MIC (paradoxical effect) accomplished by increased cell wall chitin; evidence for beta-1,6-glucan synthesis inhibition by caspofungin. Antimicrob Agents Chemother 50: 3160 -1.

70. Beyda ND, Liao G, Endres BT, Lewis RE, Garey KW (2015) Innate inflammatory response and immunopharmacologic activity of micafungin, caspofungin, and voriconazole against wild-type and FKS mutant Candida glabrata isolates. Antimicrob Agents Chemother 59: 5405-12.

71. Galan-Diez M, Arana DM, Serrano-Gomez D, Kremer L, Casasnovas JM, et al. (2010) Candida albicans beta-glucan exposure is controlled by the fungal CEK1-mediated mitogen-activated protein kinase pathway that modulates immune responses triggered through dectin-1. Infect Immun 78: 1426-36.

72. Ballou ER, Avelar GM, Childers DS, Mackie J, Bain JM, et al. (2016) Lactate signalling regulates fungal beta-glucan masking and immune evasion. Nat Microbiol 12: 238

73. Brown GD (2006) Dectin-1: a signalling non-TLR pattern-recognition receptor. Nat Rev Immunol 6: 33-43.

74. Marakalala MJ, Vautier S, Potrykus J, Walker LA, Shepardson KM, et al. (2013) Differential adaptation of Candida albicans in vivo modulates immune recognition by dectin-1. PLoS Pathog 9: 18.

75. Netea MG, Gow NA, Munro CA, Bates S, Collins C, et al. (2006) Immune sensing of Candida albicans requires cooperative recognition of mannans and glucans by lectin and Toll-like receptors. J Clin Invest 116: 1642-50.

76. Erwig LP, Gow NA (2016) Interactions of fungal pathogens with phagocytes. Nat Rev Microbiol 14: 163-76.

77. Gillum AM, Tsay EY, Kirsch DR (1984) Isolation of the Candida albicans gene for orotidine-5'-phosphate decarboxylase by complementation of S. cerevisiae ura3 and E. coli pyrF mutations. Mol Gen Genet 198: 179-82.

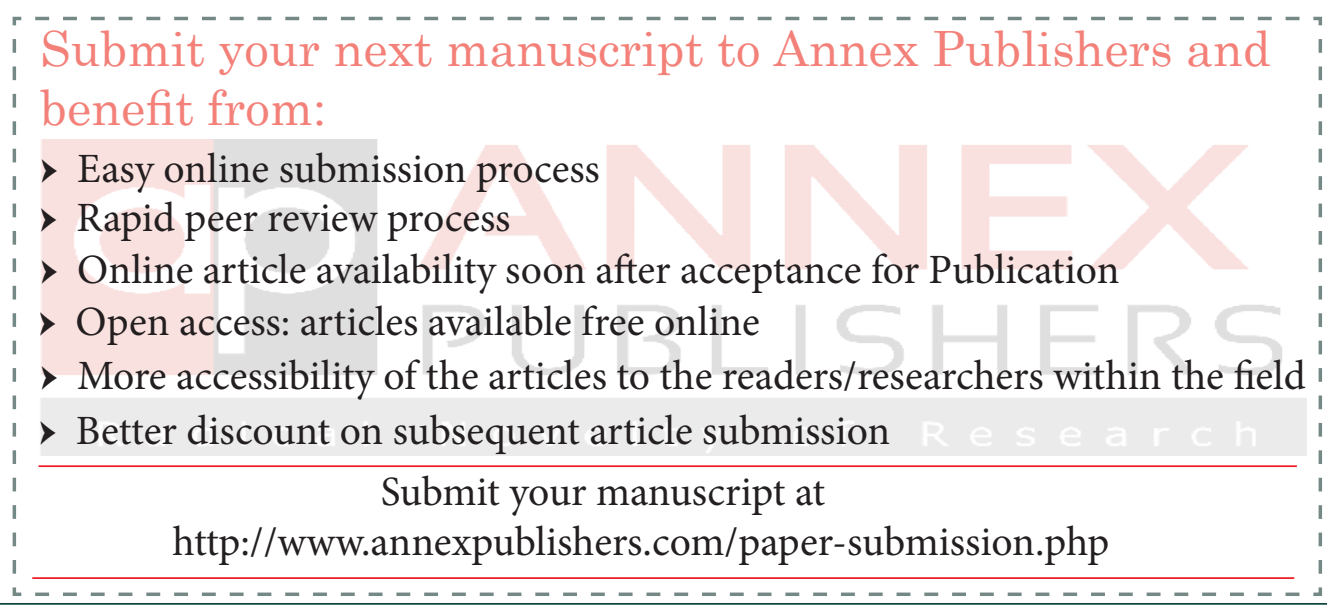

